\title{
Sequential blanking: A function of geometric analyzers in the human visual system
}

\author{
M. S. MAYZNER and M. E. TRESSELT, \\ New York University, Bronx, N.Y. 10453
}

A computer-based cathode-ray tube display system was employed to study further the sequential blanking effect as a function of the geometric propertics of the input array. Five outline squares were displayed sequentially, employing $a$ spatio-temporal ordering designed to produce blanking of two of the squares. The two blanked squares were then progressively changed into trapezoids, which produced a dramatic weakening of the blanking effect, and the results were related to a visual information processing model involving complex patterns of lateral inhibition interacting within receptive fields of varying orders of complexity within the visual cortex.

Previous work (Bell, Forster, Finnegan, Katz, LaSusa, \& Mayzner, 1969; Buchsbaum \& Mayzner, 1969; Mayzner, Tresselt, \& Cohen, 1966; Mayzner, Tresselt, \& Helfer, 1967a, b; Mayzner, Tresselt, Adrignolo, \& Cohen, 1967) disclosed an apparently new perceptual phenomenon, which we have called "sequential blanking." It was found that if an array of inputs, possessing certain geometric properties, were displayed sequentially at appropriate display rates and in certain spatial configurations, ${ }^{2}$ up to approximately one-half of these inputs might not be perceived. It was further suggested that "lateral inhibition," perhaps functionally similar to the type of lateral inhibition discussed in detail by Ratliff (1965), combined with the "receptive field" findings of Hubel \& Wiesel $(1962,1968)$ might account for our findings (Buchsbaum \& Mayzner, 1969; Mayzner, Tresselt, \& Helfer, 1967b).

The present study is concemed with a further examination of the effect of the geometric properties of the input array on sequential blanking. In a previous study (Buchsbaum \& Mayzner, 1969), also concerned with the geometric properties of the input array, it was shown that if five vertical lines of equal length were displayed in a particular irregular order at a specific input rate, two of the five lines were not perceived. However, if the two blanked lines were either sufficiently increased or decreased in length relative to the three unblanked lines, then all five lines were clearly perceived. In the present study, five outline squares are substituted for the five vertical lines, and the squares in those display locations typically blanked are progressively changed into trapezoids. The question is raised, "How much change from square to trapezoid is required to reduce sequential blanking to zero?"

\section{SUBJECTS}

Two Ss were employed in the study, both males.

The stimuli were presented on two Fairchild CRT display consoles simultaneously, both slaved to a 340 Master Display, driven by a PDP-7 digital computer. A complete description of this hardware system and its associated computer programs (software) may be found in our previous papers (Mayzner, 1968; Mayzner, Tresselt, \& Helfer, 1967a).

\section{MATERIALS}

The basic stimulus set consisted of five outline squares, $17.5 \mathrm{~mm}$ on a side, and also separated from one another by $17.5 \mathrm{~mm}$. Twenty-five millimeters directly above the middle square of this five-square display was a round black fixation point, $3 \mathrm{~mm}$ in diam, pasted to the CRT display surface. The luminance of each square was approximately $1 \mathrm{~mL}$, as measured with a Macbeth illuminome ter under steady-state conditions, and $S$ was positioned in a head-and-chin rest $1000 \mathrm{~mm}$ from the CRT display and instructed to fixate on the black fixation point. Each of the five squares was displayed sequentially for $20 \mathrm{msec}$, with a $20-\mathrm{msec}$ intersquare display time, as these display times maximize the sequential blanking effect (Buchsbaum \& Mayzner, 1969; Mayzner, Tresselt, \& Helfer, 1967b). The five squares were displayed in an order (i.e., 31425) shown previously to produce the sequential blanking effect (Mayzner, Tresselt, \& Helfer, 1967b) and is the identical display order employed in the five-vertical-line study (Buchsbaum \& Mayzner, 1969). With this display order, the squares displayed first and second, which occur in Display Locations 2 and 4, that is, on either side of the middle square of the five-square input array, are typically not perceived. Thus, $S$ typically reports seeing only three squares, the square directly under the fixation point, displayed fourth, and the two end squares, displayed third and fifth. Additional display sequences were also constructed involving the following variations. Twenty displays were constructed, in which each of the four sides of the figures displayed first and second (i.e., in Display Locations 2 and 4) were reduced in length, one at a time, from $17.5 \mathrm{~mm}$ to the following values, $15.8,14.0,12.3,8.8$, and $5.3 \mathrm{~mm}$, to yield a set of 20 trapezoids, in which the shortest side appeared, in a given figure, on either the top, bottom, left, or right side of the figure. Thus, one display sequence was composed of five squares (17.5 mm per side) and an additional 20 display sequences consisted of three squares and two trapezoids with the five different shortest sides appearing equally on all four sides of the trapezoid figures. An additional 21 displays were also constructed, in which the squares, and corresponding trapezoids, were oriented on the CRT display to appear as diamonds. Also, because of certain display hardware limitations, some of the shortest sides assumed slightly different values, as follows: $15.0,12.6,10.2,7.7$, and $5.3 \mathrm{~mm}$. All other display parameters remained the same and this orientation factor was introduced to determine if it would have any systematic effect on the phenomena under study.

\section{PROCEDURE}

Since 42 different display sequences were constructed, these 42 sequences were presented 10 times, each time in a different random order, for a total of 420 trials. For each trial, $S$ was instructed to report the number of figures perceived, and since preliminary work had shown that $S$ always saw either three or five figures, these were the two response categories employed. Thus, with 10 trials per display sequence, a S's score could vary from $0 \%$ to $100 \%$ blanking, i.e., reporting five figures on all 10 trials ( $0 \%$ blanking) to reporting three figures on all 10 trials (100\% blanking). Further, subsequent questioning of the Ss revealed that in every case when only three figures were reported, these three figures were always the three squares in Display Locations 1, 3, and 5.

Table 1

Per Cent Blanking as a Function of Side Length

\begin{tabular}{lllllll}
\hline & & \multicolumn{5}{c}{ Side Length } \\
\cline { 2 - 6 } & Equal Sides & \multicolumn{4}{c}{ Shortest Side of Trapezoid } \\
\hline \multirow{3}{*}{ Square Orientation } & $17.5 \mathrm{~mm}$ & $15.8 \mathrm{~mm}$ & $14.0 \mathrm{~mm}$ & $12.3 \mathrm{~mm}$ & $8.8 \mathrm{~mm}$ & $5.3 \mathrm{~mm}$ \\
& $90 \%$ & $68 \%$ & $40 \%$ & $14 \%$ & $4 \%$ & $3 \%$ \\
Diamond Orientation & $17.5 \mathrm{~mm}$ & $15.0 \mathrm{~mm}$ & $12.6 \mathrm{~mm}$ & $10.2 \mathrm{~mm}$ & $7.7 \mathrm{~mm}$ & $5.3 \mathrm{~mm}$ \\
& $80 \%$ & $63 \%$ & $44 \%$ & $29 \%$ & $11 \%$ & $6 \%$ \\
\hline
\end{tabular}


RESULTS AND DISCUSSION

In the present study. each of the two Ss that were employed received +20 trials. 10 trials on each of the 42 different display sequences that were examined. Since the results for the two Ss employed were almost identical, their results were averaged and are shown in Table 1. Also, since the results of both Ss yielded almost identical results on each of the four shortened sides (i.e., top, bottom, left side, and right side) of the trapezoid figures, these findings were combined into a single composite average, which is based on 40 trials for each $S$ for each of the five side-length values that were examined, rather than being based on 10 trials for each $S$, as obtains for the equal side-length condition.

It is very clear from an examination of the results shown in Table 1 that per cent blanking of the figures in Display Locations 2 and 4 is close to $100 \%$ when all five figures enjoy the exact same geometrical properties, i.e., when all five figures are squares. However, as the squares in Display Locations 2 and 4 progressively change into trapezoids, it is equally clear that blanking is dramatically reduced. Further, this reduction in the blanking effect appears to be independent of figure orientation, i.e., square vs diamond.

Perhaps the most intriguing result shown in Table 1 is that for every 2- to $3-\mathrm{mm}$ increment of shortening of one of the four sides of the figures in Display Locations 2 and 4 , per cent blanking drops about $20 \%$. Thus, by shortening any given side by approximately $10 \mathrm{~mm}$, there is a change from almost $100 \%$ blanking to essentially $0 \%$ blanking. In contrast, in our previous study (Buchsbaum \& Mayzner, 1969), employing an identical paradigm with five vertical lines in place of the five figures employed in the present study, line length had to change from 40 to $50 \mathrm{~mm}$ to produce an equivalent drop from $100 \%$ to $0 \%$ blanking. However, since in the previous study (Buchsbaum \& Mayzner, 1969) line length was initially $50 \mathrm{~mm}$, in comparison to the present $17.5 \cdot \mathrm{mm}$ squares, while the absolute values of change needed to eliminate the blanking effect are quite different, the relative values are quite similar. This finding immediately raises the question with both the vertical line and square-diamond paradigms: if we were to vary line length (e.g., 25,50,75 mm) or square size (e.g., 17.5, 25, $50 \mathrm{~mm})$, would the blanking effect, as a function of differences in line length or trapezoid size in Display Locations 2 and 4, remain invariant over a relatively wide range of dimensions or sizes?

Overall. the results of the present study and those found previously (Buchsbaum \& Mayzner, 1969) tend to confirm our earlier position (Mayzner, Tresselt, \& Helfer,
1967 b) that "By varying orientation. angle size. degree of curvature. length, etc.., and observing which of these input features are related to sequential blanking effects and which are not, it may be possible to establish the invariant dimensions of feature extraction processing and to assess in de tail the processing rules exercised by the visual system in form and pattern perception [pp. 103-104]." Extending this position further, we would suggest that the sequential blanking technique may allow for the specific identification of basic "geometric analyzers" within the human visual system, functionally equivalent to the "geometric analyzers" (e.g., line orientation detection systems) that Hubel \& Wiesel (1962,1968) are mapping out in the cat and monkey striate cortex.

As we suggested earlier (Buchsbaum \& Mayzner, 1969: Mayzner, Tresselt, \& Helfer, $1967 \mathrm{~b})$, sequential visual inputs having identical but simple geometrical properties (such as vertical lines) are most probably mapped within the same "column," following the terminology of Hubel \& Wiese $(1962,1968)$, within the visual cortex. We also speculated that inputs processed in the same columns, if certain spatial and temporal orderings obtained, would be influenced by patterns of lateral inhibition, perhaps functionally similar to the type of lateral inhibition discussed in detail by Ratliff (1965), thus giving rise to the sequential blanking effects that have been found.

The results found in this study with sequential visual inputs possessing more complex geometric properties (such as squares and trapezoids), now begins to suggest that either more complex geometric configurations may be processed within the same column within the visual cortex, or, more likely, many different columns may be involved, each associated with some basic geometric property of the input configuration, such as, line length, angle size, etc. Thus, the underlying neural (functional) architecture involved may be different for the processing of sequentially displayed vertical lines vs squares or trapezoids, but since blanking does occur in both cases, it seems plausible to assume that some type of lateral inhibition also is operating in both cases, again occurring more readily within the same column or columns subserving the same geometric analyzing function (i.e., equal line lengths or equal squares) than between columns subserving different geometric analyzing functions (i.e., different line lengths or squares vs trapezoids).

Finally, an interesting next step in studying the effects of geometric analyzers on sequential blanking would be to increase the geome tric complexity of the input array further. For example, using the same paradigm, suppose we substitute five Necker cubes in place of the five squares of the present study. This type of input array raises two relevant questions: (1) Since Necker cubes show reversing perspectives, would blanking perhaps even occur, unless all five cubes were perceived at any given instant in the same perspective? (2) What geometric changes would be necessary to eliminate blanking effects. if such effects were found?

\section{REFERENCES}

BELL, A., FORSTER, R. G, JINNEGAN, F. J.. KATZ, M., LaSUSA, J. I., \& MAYZNER, M. S. Sequential blanking and visual form perception. Psychonomic Science, 1969, 15, 103-104.

BUCHSBAUM, W. H., \& MAYZNER, M. S. The elfects of line length on sequential blanking. Psychonomic Science, 1969, 15,111-112.

ERIKSEN, C. W., \& SPENC ER, T.J. Visual search under conditions of very rapid sequential input rates. Perception \& Psychophysics, 1968, 4, 197-202.

HUBEL, D. H., \& WIESEL, T. N. Receptive fields, binocular interaction, and functional architecture in the cat's visual cortex. Journal of Physiology, 1962, 160, 106-123.

HUBEL, D. H., \& WIESEL, T. N. Receptive ficlds and functional architecture of monkey striate cortex. Journal of Physiology, 1968, 195 , 215-243.

MAYZNER, M. S. The research potential of a computer-based cathode-ray tube display systcm. Behavior Research Methods \& Instrumentation, 1968, 1, 41-43.

MAYZNER. M. S., TRESSELT, M. E., \& COHIN, A. Preliminary findings on some effects of very fast sequential inputs on perception. Psychonomic Science, 1966, 6, 51 3-514.

MAYZNER, M. S., TRESSELT, M. E., \& HELFER, M. S. A research strategy for studying certain effects of very fast sequential input rates on perception. Psychonomic Monograph Supplements, 1967a, 215. Whole No. 21), 73-81.

MAYZNER, M. S., TRESSELT, M. E.. \& HELFER, M. S. A provisional model of visual information processing with sequential inputs. Psychonomic Monograph Supplements, 1967b, 2(7, Whole No. 23), 91-108.

MAYZNER, M. S., TRESSELT, M. E., ADRIGNOLO. A. J., \& COHEN, A. lirther preliminary findings on some effects of very fast sequential input rates on perception. Psychonomic Science, 1967, 7, 281-282.

RATLIFF, $\mathrm{F}$. Mach bands: Quantitative studies on neural networks in the retina San Francisco: Holden Day, 1965.

1. This research was supported by Grant No. GB-8037 from the National Science Foundation to the first author.

2. Spatial configuration, i.c. the spatial relationship the inputs of the input array bear to one another, is obviously an important factor in the sefuential blanking effect. sine our previous work (Mayzner, Tresselt \& Helfer. 1967a, b) has shown (1) the effect to obtain only over a visual angle of about $4 \mathrm{deg}$ and (2) to obtain for horizontal. vertical, and oblique arrays. whilc liriksen \& Spencer (1968) have, with different hardware and experimental procedures. however. failed to find sequential blanking with a circular array. Distance and spatial arrangement of inputs are currently under vtudy 